MUZIKOLOŠKI ZBORNIK - MUSICOLOGICAL ANNUAL IV, LJUBLJANA 1968

\title{
ZADARSKI NEUMATSKI FRAGMENTI V OXFORDU
}

\author{
Bojan B u ji ć (Sarajevo)
}

Med številnimi srednjeveškimi dalmatinskimi rokopisi $\mathrm{v}$ oxfordski Bodleian Library izstopata dva, ki sta nenavadno zanimiva za zgodovino naše srednjeveške glasbe. Do nedavnega so ju muzikološke študije pri nas docela ignorirale, čeprav so nanju že na začetku tega stoletja opozorili angleški avtorji. Rokopisa sta pripadala zbirki beneškega jezuita M. L. Canonicija, ki jo je leta 1817 odkupila od njegovih dedičev Bodleian Library, strokovnjaki pa so ju imeli nekaj časa za italijanska. Šele po podrobnem preučevanju konec 19. stoletja se je pokazalo, da rokopisa izvirata iz Zadra in da sta bila last ženskega benedektinskega samostana sv. Marije. ${ }^{1}$ Danes imata signaturo Canonici Liturg., MS 277 (Horae monasticae - Officia et preces siglum H.M.) in Canonici Bib. lat. MS 61 (Evangeliarium Vekenegae, siglum E.V.). Transkripcijo Exulteta iz drugega rokopisa in detajlno in argumentirano študijo o njem je nedavno objavil Marijan Grgić. ${ }^{2}$

Rokopis H.M. je bil napisan sredi 11. stoletja v skriptoriju samostana sv. Krševana v Zadru za Čiko, sestro kralja Petra Krešimira IV, ki je leta 1066 obnovila samostan sv. Marije in umrla kot njegova opatinja verjetno leta 1095. Celo površen pregled koledarja v H.M. (fol. 4-18) nam pokaže slovanska imena: na fol. 8' stoji za 25. april obiit dabrus abbas; na fol. 11' (3. julij) obiit dabrazza (Dabrača); na fol. 13' (29. avgust) obiit domazza (Domača). To pa je že Nicholsonu pomagalo, da je ne glede na ostale dokaze dognal izvor rokopisa. ${ }^{3}$ Glavni del rokopisa, kamor spada tudi koledar s temi imeni, končuje $\mathrm{s}$ fol. 147 in je $\mathrm{v}$ beneventanski notaciji 11. stoletja. Zatem obsegajo folie $147^{\prime}-153^{\prime}$ homilijo Visio beati Pauli apostoli, ki je zapisana $\mathrm{v}$ minuskuli 12. stoletja, tu pa se skoro sredi teksta homilije na fol. $150^{\prime}$ pojavi sedem vrstic zapisa $v$ neumah. Zadnja beseda $v$ tekstu homilije na predhodnji strani (fol. 150) ni dokončana: et serpen... in potem se na fol. $150^{\prime}$ šele za neumatskim fragmentom

1 Podrobno o njunem nastanku in poti iz Zadra $\mathrm{v}$ Oxford glej Većenegin evandelistar: V. Novak, Notae paleographicae, Starine 51 JAZiU, Zagreb 1962, str. $5 \mathrm{ff}$.

${ }_{2}$ M. Grgić, Najstarije zadarske note, Radovi instituta JAZiU u Zadru, zv. XI-XII, Zadar 1965, str. 269-352.

3 E. Nicholson, Early Bodleian Music, London 1913, knj. III, str. 74-75. 
nadaljuje: ...tes. Po tem kot po arhaičnem videzu teksta v neumatskem fragmentu, bi se dalo sklepati, da je fragment starejši kot homilija. Neume so beneventanske in zapisane so na črtah. Vendar to danes za transkripcijo zelo malo pomeni. Črte, ki so, kot je videti, tri, so potegnjene zelo bledo, sčasoma pa so še bolj pobledele in tako pri dešifriranju ne pomaga niti branje pod ultravioletnimi žarki. V korekturah $\mathrm{k} \mathrm{V}$. knjigi kataloga Bodleianske biblioteke komentira Nicholson leta 1905: »(neume) so napisane na zelo obledelem enobarvnem sistemu treh črt, od katerih je jasno vidna le druga. $\left(^{4}\right.$ C̆as je od tedaj napravil svoje in danes lahko črte le še s težavo zapazimo. Ni niti oznak za višino, kar vse znatno otežuje transkripcijo. Zaradi tega je transkripcija, ki jo prinašam tu, na posameznih mestih približna in tako nikakor ne mislim, da se je ne da korigirati.

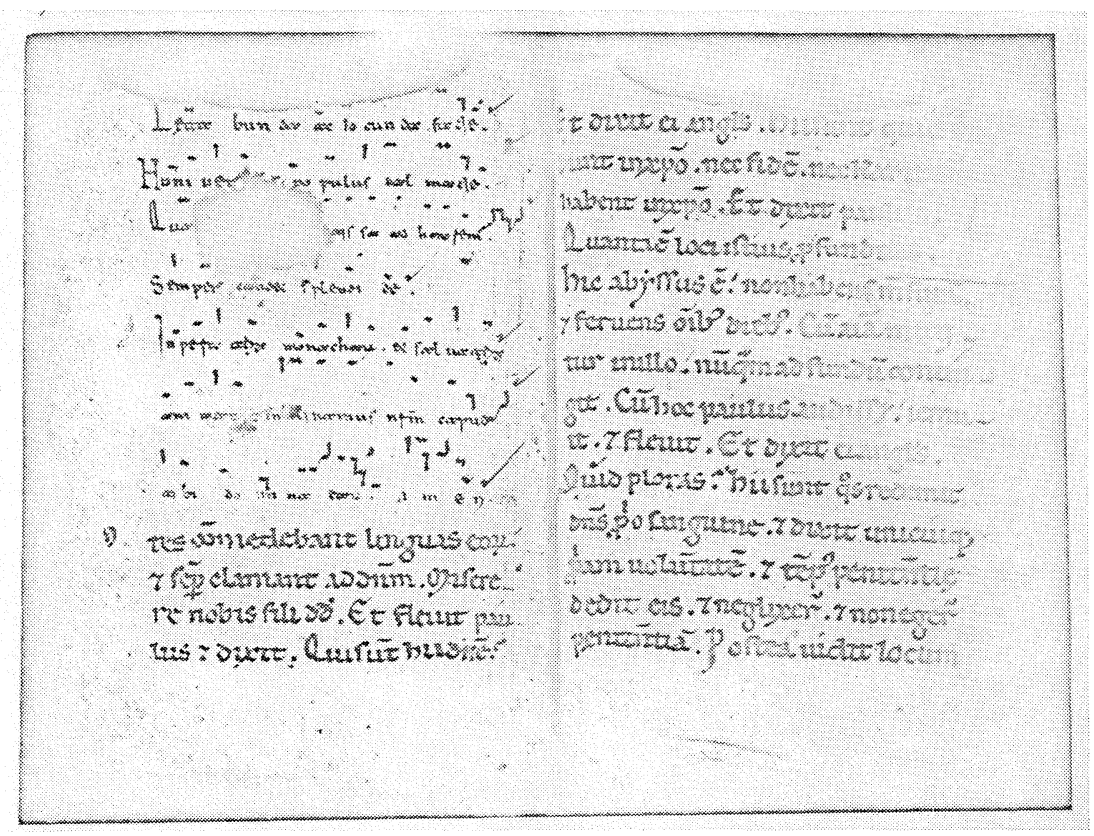

MS Canonici Liturg. 277, fol. 150'-151, Oxford, Bodleian Library

Vse folije rokopisa od fol. 138 naprej so na vrhu poškodovane, zaradi česar je neume $\mathrm{v}$ prvi vrsti težko prebrati, medtem ko so nekatere čisto uničene. Zato so tisti toni, ki so rekonstruirani po videzu in položaju neum v drugi vrsti, postavljeni v oklepaje. Transkripcija zadnje vrste je otežkočena, ker se obseg napeva poveča, in so neume postavljene neprecizno. Številke od 1 do 4 z leve označujejo razdelitev teksta, tako kot je to na-

${ }^{4}$ F. Madan, A Summary Catalogue of Western Manuscripts in the Bodleian Library, Oxford 1905, knj. V, str. XV. 
pravil Nicholson. ${ }^{5}$ Ta namreč meni, da je celoten fragment dejansko sestavljen iz delov štirih himnusov in poskuša tako rekonstruirati celo tretjo možno vrstico, ki bi se morala po njegovem nekako takole glasiti: Laudat clarum nomen Anastasie. Gotovo je, da manjka del teksta in glasbe izza druge vrste, saj relativno nižji ton na začetku tretje vrste ne ustreza visokemu custosu na koncu druge vrste. Vendar bi mogli prej reči, da so deli 1-3 fragmenti neke večje celote, medtem ko Inperatrix monacharum predstavlja drugi himnus. Druga beseda v tretji vrsti teksta je skoro nečitljiva, a prav ta bi lahko bila zelo pomembna za datiranje fragmenta. Nicholson in Lowe ${ }^{6}$ se strinjata, da beseda začenja $\mathrm{z}$ ro in da končuje $\mathrm{z} a$. Nicholson jo bere kot rosata, toda ne $\mathrm{v}$ smislu lastnega imena, ampak kot particip »kronana z rožami๔. To bi bilo tudi sprejemljivo, toda Nicholsonu ni bilo znano, da je bilo eni od opatinj sv. Marije ime Rosana (11701183 ), ${ }^{7}$ zaradi česar je mnogo bolj verjetno, da je treba brati kot rosana abbatissa. To omogoča, da za zdaj domnevamo, da je predzadnje desetletje 12. stoletja čas, ko je bil fragment zapisan. Nepopolnost fragmenta kakor tudi dejstvo, da se pojavlja custos, tj. znak, ki naznačuje peveu višino tona $\mathrm{v}$ naslednji vrsti, tudi izza poslednje neume pri končni besedi Amen, kaže na to, da gre samo za del neke večje celote, ki je tu prepisan morda le za vajo. ${ }^{8}$

Najvažnejša melodična značilnost teh fragmentov je karakteristični postop od tonike $f$ za dve veliki sekundi navzgor do $a$ in zatem postopna vrnitev na $f . \mathrm{V}$ drugem himnusu pade razen tega tudi $\mathrm{v}$ oči doslovno, a zatem sekvenčno ponavljanje začetnega motiva štirih tonov $(f-g-a-f)$ : Inperatrix $=$ monacharum $=$ et saluatrix $($ sekv. $)=$ animarum $($ sekv. $)$. Ta značilen melodični postop, namreč sekvenčna obravnava motiva in neka enoličnost, kaže na podobnost zadrskih fragmentov s himnusima $O$ veneranda trinitas in Christus celorum habitator iz nekega himnarija 12. stoletja, ki je sedaj v Rimu (Biblioteca Casanatense, MS 1574.). Himnarij izvira iz Gaete, zanimivo pa je, da se himnus $O$ veneranda trinitas nahaja v himnariju v Bariju, San Nicola (brez inventarne številke). ${ }^{9}$ Napev iz Zadra pa ni toliko soroden s tistimi iz Gaete in Barija, da bi mogli govoriti o direktnem kopiranju iz kateregakoli italijanskega vira. Najbolj verjetno je, da pripadajo himnusi istemu melodičnemu tipu, $\mathrm{ki}$ je bil razširjen na območju vpliva južnoitalijanskih benedektincev. Tekst zadarskih himnusov, $\mathrm{v}$ katerem se omenja huniuersus populus dalmacie in ime opatinje Rosane, je nedvomno nastal v Zadru, medtem ko je bil himnus lahko komponiran po zgledu nekega drugega himnusa, ki je bil tu $\mathrm{v}$ rabi.

5 E. Nicholson, op. cit., str. 74.

${ }^{6}$ E. A. Lowe, Scriptura Beneventana, Oxford 1929, knj. II, št. LXXV.

7 Većenegin Evandelistar; B. Telebaković-Pecarski, Notae artis illuminatoriae. Starine 51 JAZiU, Zagreb 1962, str. 58.

8 Rokopis H. M. vsebuje še glasbene zapise iz poznejšega časa. Lista 2 in 3 sta bila dodana pri poznejšem vezanju in vsebujeta Marijin himnus $v$ notaciji poznega 13. stol., čigar začetek in konec manjkata. Na praznem prostoru na fol. 153' je nekdo na koncu 13. ali na začetku 14. stol. dopisal Alleluia in začetek himnusa $O$ mediatrix hominum.

9 B. Stäblein (ur.): Hymnen I, Monumenta monodica medii aevi, I, Kassel in Basel 1956, str. 422 in 608. 
Drugi zadarski neumatski rokopis v Oxfordu, E. $V$., vsebuje od fol. 115 do fol. 123 Exultet za Veliko soboto in je napisan tudi v beneventanskih neumah. M. Grgiću je uspelo pokazati, da je bil Exultet prepisan leta 1095 ali 1096 iz neke predloge, ki je morala nastati med leti 1073 in $1078 .^{10} \mathrm{~V} E . V$. so neume skrbno razmeščene okrog ene linije, ki je vtisnjena $\mathrm{v}$ pergament $\mathrm{s}$ trdim predmetom. Če primerjamo $\mathrm{s}$ temi za devetdeset let mlajše neume iz fragmenta v H. M., opažamo, da se slednje po obliki ne razlikujejo od neum $\mathrm{v}$ E. V. Kljub danes obledelemu tričrtnemu sistemu $\mathrm{v}$ H. M. pa je izvedeno spacioniranje okrog ene črte v $E$. $V$. dosti bolj skrbno. Oznake za višino se $\mathrm{v} H$. M. še ne pojavljajo. Vse to nas nagiblje k misli, da je morda fragment starejši od časa, ko je živela opatinja Rosana, kar potem spet vključuje vprašanje, ali ni treba branje rosana zamenjati za verjetno pomanjševalno Nicholsonovo rosata. To pa je seveda težko sprejemljivo in tako nam ne preostane nič drugega, kot da se za enkrat zadovoljimo $\mathrm{z}$ domnevami:

a. fragmenti $H$. M. so prepisani morda za vajo iz nekega identičnega sodobnega izvlečka, v katerem so bili himnusi tudi nepopolni;

b. fragmenti so prepisani iz nekega popolnejšega himnarija, čigar sled je danes izginila;

c. fragmenti predstavljajo kombinacijo več virov: novi tekst je postavljen že pod obstoječo melodijo, ki je ali prevzeta iz tujega vira ali pa zložena v Zadru.

Edini gotov sklep, ki ga moremo napraviti iz teh podmen, je, da je moral biti nek popolnejši himnarij, bodisi iz časa opatinje Rosane ali pa starejši, ki je vseboval večje število melodij. Samostanske biblioteke v Dalmaciji so doživele toliko opustošenj, medtem ko je bilo rokopisno gradivo odneseno, da je težko verjeti, da se je ta starejši himnarij v celoti ohranil. Morda bi, če bi pregledali dalmatinske in tuje arhive, le našli neki podatek ali še kakšen podoben fragment, ki bi stvar bolj osvetlil. Šele ko nam bo dostopno večje število napevov, bomo lahko $\mathrm{z}$ neko gotovostjo govorili tudi o posebnostih dalmatinskega glasbeno liturgičnega repertoarja.

Ker je bila Dalmacija področje, na katerem so se srečavale tradicije vzhodne in zahodne cerkve, bo treba pri preučevanju glasbeno liturgičnih virov, a še zlasti pri melodični analizi napevov, posvetiti veliko pozornost iskanju in določanju eventualnih vzhodnih elementov $v$ sklopu latinskega liturgičnega repertoarja. Za neposredne stike na glasbeno liturgičnem področju nimamo še nikakršnih dokazov, vendar lahko upamo, da jih bomo našli, ker najdemo indikacije $\mathrm{v}$ dokumentih, ki govore na splošno o stikih liturgičnih tradicij. Neke vire je v tem primeru vredno citirati, ker izvirajo iz časa neposredno za nastankom fragmentov iz $H$. $M$. Tako papež Inocent III. v pismu, ki ga je naslovil kapitlju zadarske cerkve sv. Anastazije februarja 1.1198, ugovarja glede uporabe grškega in narodnega jezika v liturgiji:

10 M. Grgić, op. cit., str. $340-347$. 


\begin{abstract}
„Cum igitur in ecclesia vestra, que sub obedientia sedis apostolice perseuerans Grecorum hactenus et ritum seruauerit et linguam per laicalem potentiam preter vestrum auctoritatem et electionem vestram non tam latinus quam barbarus fit intrusus, nos de fratrum nostrorum consilio intrusionem ipsam irritam decernentes, ...11
\end{abstract}

Če upoštevamo bizantinski kulturni vpliv na dalmatinski obali v 11. in 12. stoletju, je mogoče domnevati, da se grški elementi v bogoslužju niso omejevali samo na uporabo jezika. V bogoslužju je jezik neločljiv od napeva in tako lahko $\mathrm{z}$ gotovostjo trdimo, da so $\mathrm{v}$ Zadru še pred koncem 12. stoletja uporabljali napeve, ki niso spadali $\mathrm{v}$ repertoar zahodnega korala.

Drugi zanimiv podatek ni dosti mlajši od pisma Inocenta III. in izhaja iz pisma Vukana, brata Štefana Prvovenčanega, istemu papežu januarja leta 1199. Vukan poroča papežu, da je odredil, da se laudum preconia poje na čast papežu na ozemlju, ki ga je Vukan spravil pod svojo oblast:

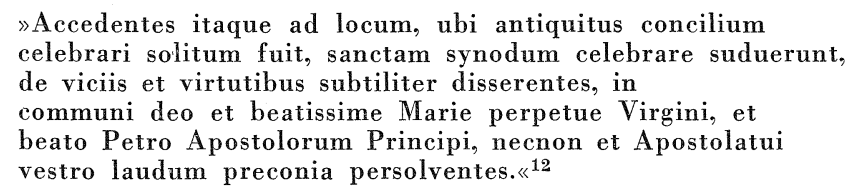

Vukan in Štefan sta se, ko sta izrabljala trenutno slabost Bizanca, obračala $\mathrm{k}$ papežu in Ogrski, ker sta pričakovala pomoč in podporo. V bistvu je to bila politična igra, $v$ kateri je na obeh straneh $v$ mnogočem ostalo le pri praznih obljubah. Vendar je papež od časa do časa pošiljal poslance, ki so morali poročati o izvrševanju prevzetih obvez. Koliko je obstajal dejanski neposredni vpliv teh poslancev, lahko le ugibamo, je pa zelo verjetno, da so bili osamljeni poskusi, da se v bogoslužje bizantinskega tipa uvajajo nekateri napevi iz repertoarja zahodne cerkve.

Le malo je upanja, da bomo našli $\mathrm{v}$ pisanih virih dokaze o stikih vzhodne in zahodne glasbeno liturgične tradicije na našem ozemlju. Ob tem pa ne smemo nikdar pozabiti, da tisto, kar vidimo $\mathrm{v}$ zgodovini liturgične glasbe iz današnje perspektive $v$ navidezno ločenih kategorijah, ni obstajalo $\mathrm{v}$ identičnih kategorijah $\mathrm{v}$ zavesti predstavnikov cerkve $\mathrm{v} 12$. stoletju. Glede na to tudi ne moremo pričakovati preciznejših verbalnih opisov. Edine dokaze, na katere lahko upamo, moremo izpeljati iz podrobne melodične analize obstoječih fragmentov. $\mathrm{V}$ primeru zadrskih napevov iz $H$. M. je očitno sorodstvo z južnoitalijansko tradicijo. V nekaterih drugih primerih pa - dalmatinske in tuje biblioteke imajo gotovo še fragmente, ki so doslej ostali še neopaženi - ne bo nekaj nenavadnega, če bomo morali iskati sorodstvo $\mathrm{v}$ sestavu bizantinske glasbe.

11 T. Smičiklas (ur.), Diplomatički zbornik kraljevine Hrvatske, Dalmacije $i$ Slavonije, Zagreb 1904, knj. II, str. 289-290. str. 6 .

12 A. Theiner, Vetera monumenta Slavorum meridionalium, Rim 1863, knj. I, 


\section{SUMMARY}

The Canonici collection of manuscripts in the Bodleian Library, Oxford contains a number of MSS of Dalmatian provenance of which two (Canonici Bib.lat., MS 61 and Canonici Liturg., MS 277) are of particular importance for the early history of liturgical music in this part of the world. The former of the two MSS contains a complete Exultet hymnus written probably in the last decade of the 11th century and the latter MS has, on fol. 150', fragments of some hymns written in beneventan neumes probably towards the end of the 12th century. Owing to the damage of the folio some neumes and one important word of the text cannot be read at all and the lines on which the neumes were written are now hardly visible. In spite of this, an attempt has been made to transcribe the music and the present writer is inclined to believe that the folio contains the fragments of two hymns copied from another, probably larger, source. There is a strong melodic similarity between the hymns from Zadar and some contemporaneous sources of South Italian provenance. Direct contact between the Italian and Dalmatian sources cannot be supposed but the existing similarity is easily explained by the fact that all these melodies came from the region in which the activity of the South Italian Benedictines was strongly felt.

It may be added that the Dalmatian liturgical repertory from the 11th and the 12th centuries is well worth studying. During these two centuries Byzantine influence was strongly felt on the Dalmatian coast and further researches into the melodic nature of this repertory may easily reveal some new data about the contacts between the Eastern and the Western chants. 